Microbiology Societies (IUMS). As an independent society, ISME has organized highly successful international symposia in Halifax (1998), Amsterdam (2001), Cancun (2004) and Vienna (2006). The number of participants in our symposia continues to increase, reflecting the surge in interest in microbial ecology, from 300 participants in Dunedin, New Zealand in 1977 for the inaugural meeting of ICOME, to an impressive gathering of more than 2000 attendees at ISME-11 in Vienna last year. This meeting attracted participants from 65 countries representing all geographic regions. We especially cherish the ongoing participation of a large number of graduate students and young scientists at our symposia, indicating a very healthy future of ISME and the discipline of microbial ecology.

The field of microbial ecology does not adhere to boarders and requires effective cooperation to foster discipline at the international level. It is the objective of The ISME Journal to facilitate these interactions. We sincerely hope that the ISME Journal will serve as an important platform to promote microbial ecology to the scientific community at large and also effectively clarify and inform the broader community and decision makers of the pivotal role of microorganisms in the well-being of life on Earth and our communal future.

$Y$ Cohen (ISME President 2001-2004), is at the Faculty of Science, The Alexander Silberman Institute of Life Sciences, Hebrew University of Jerusalem, Jerusalem, Israel. E-mail: yehucoh@vms.huji.ac.il; $S$ Kjelleberg (ISME President 2004-2006), is at the School of Biotechnology and Biomolecular Sciences, University of New South Wales, Sydney, New South Wales, Australia. E-mail: skjelleberg@science.unsw.edu.au and HM Lappin-Scott (ISME President 2006-2008), is at the School of Biosciences, University of Exeter, Exeter, Devon, UK. E-mail: H.M.Lappin-Scott@exeter.ac.uk

\title{
Microbial ecology and environmental biotechnology
}

\author{
Willy Verstraete
}

The ISME Journal (2007) 1, 4-8; doi:10.1038/ismej.2007.7

\section{The domain}

Environmental biotechnology deals with the microbiota in the water, air and soil surrounding us; moreover, the gastrointestinal tract, that is the 'outside world inside the living animals' is also often considered to be part of the environmental biotechnology domain (Figure 1). In these open systems, the microbial communities are complex and constantly changing. One can consider these communities as accidental assemblages or as metagenomic functional units (Tringe et al., 2005). An important issue is that they represent superb resources in terms of genes and functionalities. Yet, there is much more possible and necessary than the mere listing of DGGE/T-RFLP/clone libraries. The key point for the next decades is to deal with the proper management of these microbial resources. At all levels of our society, the concept of human resource management has become of preponderant importance and plenty of top-ranking business schools develop it; in the domain of environmental biotechnology, the focus for the next decades must be on microbial resource management (MRM).

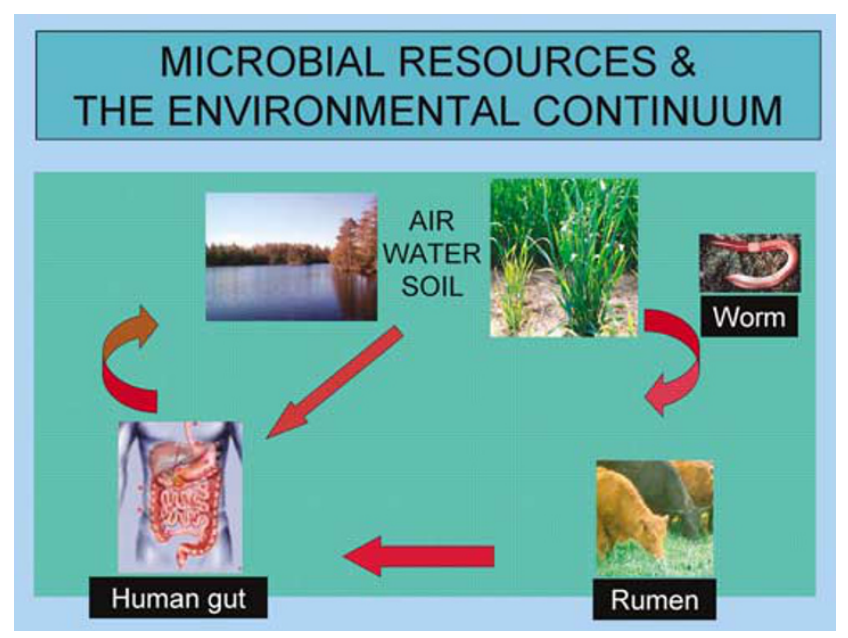

Figure 1 Schematic representation of the various domains covered by environmental biotechnology. 


\section{The essential research}

To properly manage complex microbial systems, the technologist needs well-documented concepts, reliable tools and a set of default values. In that respect, there is much to be done in terms of MRM. Actually, the microbial ecologists and environmental microbiologists have to address a new mindset. They rely still heavily on the Beijerinck concept that most microorganisms are 'everywhere'; yet, there are clear cases where bioaugmentation is needed to successfully remediate disturbed environments (Boon et al., 2002; Vaithiyanathan et al., 2005; Maes et al., 2006). They also have to come to terms with the Darwinbased niche assembly concept that assumes that nature has a series of tasks to which organisms adapt. At present, they must consider the Hubbell neutral theory which seems to support more observed patterns in nature (Hubbell and BordaDe-Agua, 2004). It states that the influx of new species is of preponderant importance in creating new niches and that organisms actually engineer their own tasks and niches. There is also, in terms of species distribution, the well-known macroeconomic Pareto 80/20 principle according to which $80 \%$ of all energy (labour) flux is normally acquired by $20 \%$ of the participants (Figure 2) (Dejonghe et al., 2001); the latter is useful to interpret the normal, respectively, distorted functioning of microbial communities in open ecosystems and can be derived from microbial community DGGE patterns (Mertens et al., 2005). Finally, there is the concept that one should hope for a 'stable' microbial community to establish in a particular system; yet, it has become evident that normally there is a continuous change and succession of cooperative consortia (Curtis and Sloan, 2004). Hence, the key question is how to judge and benchmark the rate of these successions and the resilience of the community to stress. Of course, microbial ecology has at present a variety of new molecular tools but to

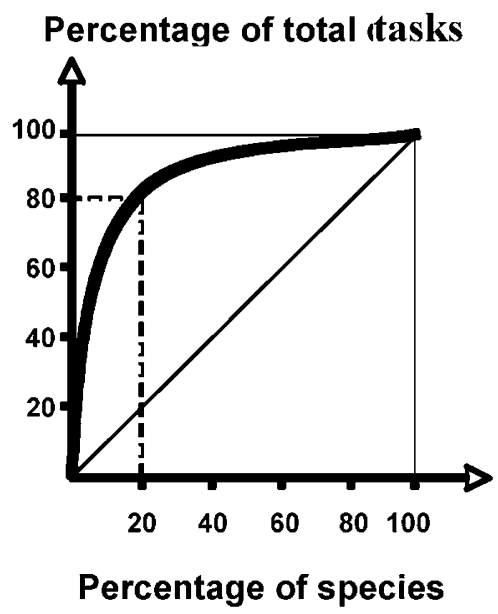

Figure 2 The Pareto curve relates the distribution of participants to the total amount of tasks achieved. upgrade its knowledge base to the level of MRM, one has to develop a series of typical parameters, which allow to characterize if the community receives a broad or a narrow influx of species, if it is fully operational and if it exhibits a normal rate of change in terms of metagenomic composition. Most of all, engineers urgently need default values for each of these parameters.

\section{Misplaced hopes}

Lots of hopes have been raised that one would be capable to steer microbial conversions in open systems by favouring co-metabolism. To the best of our knowledge, microbial selection rapidly overrules fortuitous metabolism and successful remediation requires active metabolic processes. Several means of introducing genetically modified organisms in open systems have also been explored. However, these 'super'-organisms have illustrated that in open ecosystems, the ability to cope with a multitude of challenges to survival and growth is at least as important as a specific trait to degrade a particular compound. High hopes and considerable amounts of funds have been placed on the development of genomic tools such as microarrays capable to depict the status of a multitude of genes at a particular moment for a particular site (Lajoie et al., 2002; Denef et al., 2004; Gentry et al., 2006). Although scientifically to be applauded, the latter technologies do not generate direct information on how systems containing several tens of thousands of different organisms such as the gastrointestinal tract, the soil or activated sludge actually function in terms of a micro-, respectively, a macro-economic community. The challenge for microbial ecologists is to further develop the 'metabolome' so that it allows the vital organisms to benefit from their actions within the system. Rather than constructing artificial genomes, one has to strive for techniques which allow to seed natural strains in an effective way into a community (Figure 3) (Boon et al., 2002; Watanabe et al., 2002; Vaithiyanathan et al., 2005; Maes et al., 2006). In this way, these natural microorganisms themselves can be established or their genes can be transferred to the receiving community by horizontal transfer thereby bringing about the necessary changes (Taghavi et al., 2005). Finally, in addition to the lists of bacterial species and genes found to be present at a particular site or in a microcosm, one needs to develop coherent concepts about diversity in relation to volume (Van de Gast et al., 2006) and metabolic conversions in relation to changes of free energy (Jorgensen and Gallardo, 1999; Ishii et al., 2005, 2006).

\section{Hot topics}

The super challenges of the 21st century are climate change, energy supply, health and diseases, and 


\section{HOT SPOT TUBES}

\section{3-chloroaniline (3-CA) in wastewater}

Minimal 3-CA absorption Removal by encapsulated

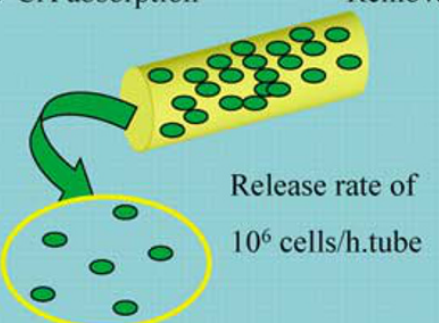
cells

$(10 \%)$

Freshly released cells with high activity

$(56 \%)$

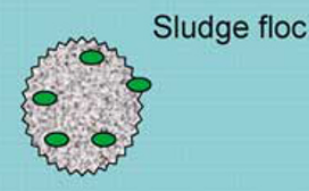

Aged cells with low activity

$(34 \%)$

Daily supply of fresh cells

Slow release structures

Figure 3 Novel techniques to introduce species in ecosystems are necessary (Boon et al., 2002).

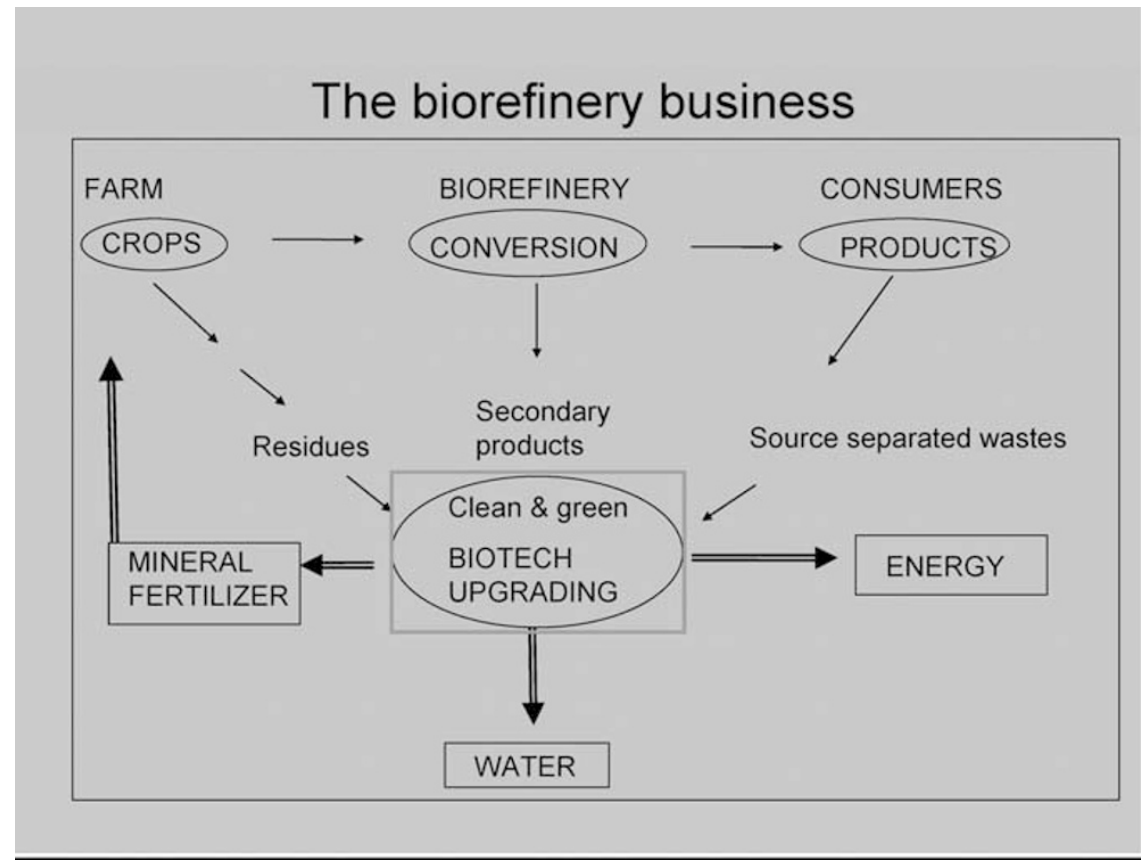

Figure 4 The bioeconomy will rely on biorefineries; the latter will require major inputs from microbial ecologists and environmental biotechnologists.

sustainable environment. MRM has an important role to play in each of these. In terms of climate change, the emission of $\mathrm{CO}_{2}$ by the soil and the possibility to sequester ample amounts of carbon in the soil by good agricultural practices constitutes a major challenge. In this context, also the prevention of $\mathrm{CH}_{4}$ emissions from wastes, agricultural practices and natural systems is a task to be taken up by environmental biotechnologists (Vande Woestyne et al., 1995). In addition, the potential exist to step up the services rendered by healthy soils to society, for instance, by removing methane from the atmosphere through the action of methanotrophic bacteria in the soil (Boeckx et al., 1997; Schimel and Gulledge, 1998; Mohanty et al., 2006). In the domain of energy supply, the various forms of bioenergy 
raise high hopes. Of special interest is the domain of bioelectricity produced in microbial fuel cells (Rabaey and Verstraete, 2005; Aelterman et al., 2006; Lovley, 2006). Yet, the sustainability of the bioeconomy will strongly depend on the constant and effective recycling of all elements in the system and the maintenance of the overall productivity of the soils supplying the raw biomaterials (Figure 4). We constantly face the evolution of (new) pathogens. The conventional concept of total eradication of the causative agents does no longer fit in the context of MRM. Proactive hygienization in which biological control agents have an active role becomes of preponderance (Verthé et al., 2004; Zhao et al., 2004; O'Flaherty et al., 2005). Aspects such as quorum sensing are part of the control strategy (Molina et al., 2003; Davidson et al., 2006). Most of all, the yes/no presence of a putative pathogen must be replaced by proper quantitative risk assessment coupled to careful control practices, based on better understanding of microbial ecology (Dewettinck et al., 2001; Signor and Ashbolt, 2006).

\section{Overall conclusions}

Environmental biotechnology and microbial ecology, based on the multitude of new molecular tools and conceptual insights, should come to terms and develop approaches that allow transparent and effective management. This will allow society to understand the multitude of services that the microorganisms render to the quality of our planet in general and to our 'environmental continuum' in particular. We should not steer away from new challenges and the unfolding of new complex interactions between various forms of microbial life. Yet, we should also intensively seek to come to terms with the complexity so that the resources it represents are effectively managed, properly used and preserved.

\section{Willy Verstraete is Professor at the Laboratory for Microbial Ecology and Technology (LabMET), Department of Biochemical and Microbial Technology, Ghent University, Ghent, Belgium E-mail: willy.verstraete@ugent.be}

\section{References}

Aelterman P, Rabaey K, Clauwaert P, Verstarete W. (2006). Microbial fuel cells for wastewater treatment. Water Sci Technol 54: 9-15.

Boeckx P, Van Cleemput O, Villaralvo I. (1997). Methane oxidation in soils with different textures and land use. Nutr Cycl Agroecosys 49: 91-95.

Boon N, De Gelder L, Lievens H, Verstraete W. (2002). Bioaugmenting bioreactors for the continuous removal of 3-chloroaniline by slow release approach. Environ Sci Technol 36: 4698-4704.

Curtis TP, Sloan WT. (2004). Prokaryotic diversity and its limits: microbial community structure in nature and implications for microbial ecology. Curr Opin Microbiol 7: 221-226.

Davidson SK, Koropatnick TA, Kossmehl R, Sycuro L, McFall-Ngai MJ. (2006). NO means 'yes' in the squid-vibrio symbiosis: nitric oxide (NO) during the initial stages of a beneficial association. Cell Microbiol 6: 1139-1151.

Dejonghe W, Boon N, Seghers D, Top EM, Verstraete W. (2001). Bioaugmentation of soils by increasing microbial richness: missing links. Environ Microbiol 3: 649-657.

Denef V, Park J, Tsoi T, Rouillard J, Zhang H, Wibbenmeyer $\mathrm{J}$ et al. (2004). Biphenyl and benzoate metabolism in a genomic context: outlining genome-wide metabolic networks in Burkholderia xenovorans LB400. Appl Environ Microbiol 70: 4961-4970.

Dewettinck T, Van Houtte E, Geenens D, Van Hege K, Verstraete W. (2001). HACCP (Hazard Analysis and Critical Control Points) to guarantee safe water reuse and drinking water production - a case study. Wat Sci Technol 43: 31-38.

Gentry TJ, Wickham GS, Schadt CW. (2006). Microarray applications in microbial ecology research. Microb ECol 52: 159-175.

Hubbell SP, Borda-De-Agua L. (2004). The unified neutral theory of biodiversity and biogeography. Ecology 85: 3175-3178.

Ishii S, Kosaka T, Hori K, Hotta Y, Watanabe K. (2005). Coaggregation facilitates interspecies hydrogen transfer between Pelotomaculum thermopropionicum and Methanothermobacter thermautotrophicus. Appl Environ Microbiol 71: 7838-7845.

Ishii S, Kosaka T, Hotta Y, Watanabe K. (2006). Simulating the contribution of coaggregation to interspecies hydrogen fluxes in syntrophic methanogenic consortia. Appl Environ Microbiol 72: 5093-5096.

Jorgensen BB, Gallardo VA. (1999). Thioploca spp: filamentous sulfur bacteria with nitrate vacuoles. FEMS Microbiol Ecol 28: 301-304.

Lajoie CA, Sayler GS, Kelly CJ. (2002). The activated sludge biomolecular database. Water Environ Res 74: 480-487.

Lovley DR. (2006). Microbial fuel cells: novel microbial physiologies and engineering approaches. Current Opin Biotechnol 17: 327-332.

Maes A, Van Raemdonck H, Smith K, Ossieur W, Lebbe L, Verstraete W. (2006). Transport and activity of Desulfitobacterium dichloroeliminans strain DCA1 during biomentation of 1,2-DCA-contaminated groundwater. Environ Sci Technol 40: 5544-5552.

Mertens B, Boon N, Verstraete W. (2005). Stereospecific effect of hexachlorocyclohexane on activity and structure of soil methanotrophic communities. Environ Microbiol 7: 660-669.

Mohanty SR, Bodelier PLE, Floris V, Conrad R. (2006). Differential effects of nitrogenous fertilizers on methane-consuming microbes in rice field and forest soils. Appl Environ Microbiol 72: 1346-1354.

Molina L, Constantinescu F, Michel L, Reimmann C, Duffy B, Defago G. (2003). Degradation of pathogen quorumsensing molecules by soil bacteria: a preventive and curative biological control mechanism. FEMS Microbiol Ecol 45: 71-81.

O'Flaherty S, Ross RP, Meaney W, Fitzgerald GF, Elbreki MF, Coffey A. (2005). Potential of the polyvalent anti-Staphylococcus bacteriophage $\mathrm{K}$ for control of antibiotic-resistant Staphocci from hospitals. Appl Environ Microbiol 71: 1836-1842. 
Rabaey K, Verstraete W. (2005). Microbial fuel cells: novel biotechnology for energy generation. Trends Biotechnol 23: 291-298.

Schimel JP, Gulledge J. (1998). Microbial community structure and global trace gases. Global Change Biol 4: 745-758.

Signor RS, Ashbolt NJ. (2006). Pathogen monitoring offers questionable protection against drinking-water risks: a QMRA (Quantitative Microbial Risk Analysis) approach to assess management strategies. Water Sci Technol 54: 261-268.

Taghavi S, Barac T, Greenberg B. (2005). Horizontal gene transfer to endogenous endophytic bacteria from poplar improves phytoremediation of toluene. Appl Environ Microbiol 71: 8500-8505.

Tringe SG, Von Mering C, Kobayashi A, Salamov A, Chen $\mathrm{K}$, Chang HW et al. (2005). Comparative metagenomics of microbial communities. Science 308: 554-557.

Vaithiyanathan S, Sheikh Q, Ku R. (2005). Effect of transinoculation of goat rumen liquor on degradation and metabolism of mimosine in sheep fed with Leucaena leucocephala leaves. Asian Austral J Anim 18: $332-339$.
Van de Gast CJ, Jefferson B, Reid E. (2006). Bacterial diversity is determined by volume in membrane bioreactors. Environ Microbiol 8: 1048-1055.

Vande Woestyne M, Gellens V, Anasi I, Verstraete W. (1995). Anaerobic digestion and inter-regional recycling of organic soil supplements. In: Marchaim U, Ney G (eds). Sustainable rural environment and energy network (SREN) - Biogas technology as an environmental solution to pollution. REUR Technical Series Number 33. FAO, Rome, pp 149-169.

Verthe K, Possemiers S, Boon N, Vaneechoutte M, Verstraete W. (2004). Stability and activity of an Enterobacter aerogenes-specific bacteriophage under simulated gastro-intestinal conditions. Appl Microbiol Biotechnol 65: 465-472.

Watanabe K, Teramoto M, Harayama S. (2002). Stable mentation of activated sludge with foreign catabolic genes harboured by an indigenous dominant bacterium. Environ Microbiol 4: 577-583.

Zhao T, Doyle MP, Zhao P. (2004). Control of listefia monocytogenes in a Biofilm by competitive-exclusion microorganisms. Appl Environ Microbiol 70: 39964003. 